\title{
International Promotion of Chinese Language in the New Era
}

\author{
An Yalun ${ }^{1}$ \\ ${ }^{1}$ Beijing Normal University, Beijing, China \\ Correspondence: An Yalun, Beijing Normal University, 19 Xinjiekouwai Street, Haidian District, Beijing 100875, \\ China.
}

Received: January 4, 2019

Accepted: February 18, 2019 Online Published: June 29, 2019

doi:10.5539/ies.v12n7p67

URL: https://doi.org/10.5539/ies.v12n7p67

\begin{abstract}
The Belt and Road Initiative (B\&R) has provided a brand new opportunity for the International Education of Chinese Language (IECL) since 2013. For the purpose of promoting Chinese language education, this article analyzes the status quo of the IECL and problems in the development of IECL, and then proposes constructive strategies for its better development under new circumstances. It is believed that the IECL should adopt "bringing in" and "going out" development strategies as well as actively explore new modes of Chinese language education. Valuing the roles of non-profit organizations and enterprises in Chinese language education under the guidance of Chinese government is also of great importance.
\end{abstract}

Keywords: The Belt and Road Initiative, the international education of Chinese language, Confucius institutes

\section{Introduction}

In 2013, borrowed from the historical concept of the Silk Road, Chinese President Xi Jinping proposed an initiative to jointly establish the Silk Road Economic Belt and the $21^{\text {st }}$ Century Maritime Silk Road for further deepening the development of China's reform and opening up. He emphasized on adhering to the principle of achieving shared growth through discussion and collaboration to set up close ties with the economy of Eurasian countries and achieve mutual benefits in economic, trade and cultural exchanges among those countries (Publicity Department of the CPC Central Committee, 2016). As the saying goes that, "Maritime transportation depends on ships while land transportation requires vehicles". During the construction of the B\&R, language is the prerequisite to paving the way for bypass. The communication of Chinese language and culture enjoys a profound history among the 65 countries along the B\&R, including 2 countries in East Asia, 11 in Southeast Asia, 8 in South Asia, 8 in Central Asia, 16 in Middle East, 16 in Eastern Europe and 4 in the Commonwealth of Independence States (CIS). Due to the significant improvement in China's comprehensive strength and economic status after reform and opening up, the Mandarin fever has begun to take place worldwide. In many countries along the $\mathrm{B} \& \mathrm{R}$, Chinese language training schools sprang on a large scale. For example, Thailand set Chinese language as the first foreign language. Facing the ever-rising fever of Chinese language, China's Hanban and Confucius Institute Headquarter distributed an annual fund of more than 1 billion RMB into establishing overseas Confucius institutes, conducting Chinese language education and cultural activities, training overseas Chinese teachers and volunteers and innovating HSK Tests, which have all witnessed remarkable achievements. Despite of this optimistic situation, it is also imperative for us to notice some existing complexities in promoting the development of the IECL under the context of global cultural competition. Hence, this paper will look at the status quo and problems of the IECL development in nations along the B\&R based on its current promotion system and study on the countermeasures of the IECL development under the new situation.

\section{Literature Review}

In the background of the $\mathrm{B} \& \mathrm{R}$, more research today focus on problems and strategies of promoting Chinese language and culture along the B\&R countries. Ke (2017) studies the development about Sino-foreign cooperative education between China and Russian Federation. He explores talents needs under the circumstance of the B\&R and argues that the imbalance and quality of language education are two confronting problems of Sino-foreign cooperative education between the countries and one effective approach to address these problems are to improve talents groups with their cultural inter-communication abilities. Chen's (2017) study focuses on how to further promote the spread of international Chinese language education. Based on the realities of universities and colleges, he predicts the trend of Chinese globalization in the environment of the $B \& R$ and 
proposes corresponding suggestions on how to accelerate the promotion of Chinese language in the next decade. $\mathrm{Du}$ (2016) points out that the characteristics of international communication of Chinese language stand out as Confucius institutes established all over the world in recent years in the background of 'One Belt and One road'. In her study, she first distinguishes international communication of Chinese language from teaching Chinese as a foreign language and then she points out that the promotion of Chinese language depends on several factors, including a country's economic strength, the attitudes toward language among the B\&R countries and various researches on cross-cultural communication. Based on Du's work, Wan's (2017) study provides suggestions for the sustainable development of Chinese international promotion from the aspects of market resource allocation, diversified platforms of promotion, building cultural bands and optimizing professional language education. It is proposed to build an open platform for sharing Chinese language and culture resources, adjusting the current pattern of Chinese international promotion, making full use of resources and building a comprehensive market research and evaluation system, so as to ensure the stable development of overseas Chinese teaching and promotion.

\section{Methodology}

This paper examines research questions such as what is the current IECL promotion system under the B\&R initiative? What are the main problems in the development of IECL? How to establish countermeasure policies for the development of IECL under the circumstance of B\&R? In order to address these questions and have a deepening understanding of the IECL, we employ a quantitative research when analyzing the growth rate of international students along the B\&R countries in China and the number of Confucius Institutes all over the world. Based on the collected data, this paper reveals existing problems in the process of promoting Chinese language from a macro level and then makes an in-depth analysis regarding to its development strategies from different levels in the future.

\section{The IECL Promotion System under the B\&R Initiative}

The promotion of IECL is dominantly conducted with personnel and resources at provincial-level management institutions coordinated under the unified command and dispatch of the central government. In response to the overall deployment of the B\&R Initiative, the Ministry of Education of China has established a relatively complete Chinese IECL and IECL promotion management system. Various provinces, municipalities and universities have also issued series of guiding documents and policies to enhance language and cultural exchange and cooperation with countries along the B\&R.

\subsection{Governmental IECL Organization and Related Policy}

At the present stage, the IECL institutions established by the Chinese government and promotion agencies mainly include the following bodies: the General Leading Group Office of the International Promotion of National Chinese Language (hereinafter referred to as Hanban); the Confucius Institute Headquarters; the Overseas Chinese Affairs Office of the State Council; the China Education Foundation and the Ministry of Culture of the People's Republic of China.

Hanban is an institution directly affiliated under the Ministry of Education of China. It is mainly responsible for supporting the education of Chinese language and Chinese culture in all nations and at all levels. It formulates, improves and promotes the standards of international Chinese teachers, the standard of international Chinese proficiency and the general courses of international Chinese teaching. It outlines, selects, and trains Chinese teachers and volunteers to go abroad; develops and implements Chinese proficiency test; guides the Confucius Institute at the Confucius Institute Headquarters in China and carries out important activities such as the "Chinese Bridge" series (Li \& Wu, 2013). Hanban and the Confucius Institute Headquarters are co-located and directly under the management of the Ministry of Education. They provide a management system for the development of IECL and play a major role in the IECL and IECL promotion. In 2017, facing the new situation of the B\&R, the Confucius Institute Headquarters first launched the conference forum of "Confucius Institute and Building a Community of Human Destiny". After having conducting an in-depth research on countries along the B\&R, drafted the Confucius Institute Development Action Plan (referred to as the Action Plan and the timely revision of the Confucius Institute Charter (referred to as the Articles of Association) (Confucius Institute Headquarters, 2018). Through the formulation of the Action Plan and the revision of the Articles of Association, the Confucius Institute will continue to optimize the global layout, steadily expand the scale of schoolrunning, continuously improve the quality of school running and actively serve the B\&R construction and the overall situation of Sino-foreign friendship and cooperation.

The Overseas Chinese Affairs Office of the State Council (referred to as the OCAC) is mainly responsible for formulating policies and plans for overseas Chinese affairs, guiding and promoting the activities of overseas 
Chinese cultural exchanges and Chinese education. In recent years, the OCAC has issued a series of policies to promote the development of overseas Chinese education. In 2013, the OCAC finalized the Implementation Plan on Chinese Language Teacher Certificate, which comprehensively designed the Chinese language teacher certificate from the aspects of professional standards, evaluation system to operational procedures, and strengthened the construction of overseas Chinese teachers and promoted the in-depth development of overseas Chinese education, which has seen important practical significance. In 2016, the OCAC compiled the Outline for the Development of the National Overseas Chinese Affairs (2016-2020), and adopted a series of measures to promote the development of IECL with the help of national initiatives, such as the B\&R construction. By far, the OCAC has initiated and completed the preparation of 7 series of "localized" textbooks for countries and regions such as the Philippines, Cambodia, Indonesia, Thailand, Myanmar and Central Asia. Nearly 3,200 Chinese language teachers from 11 countries along the B\&R including Thailand, Indonesia and Laos have been invited to the teachers' training in China. Altogether 18 lecture groups were sent to 6 B\&R countries including Philippines, Malaysia and Cambodia and 5,500 Chinese language teachers received trainings (Overseas Chinese Affairs Office, 2018).

Under the supervision of the OCAC, the Chinese Language and Culture Education Foundation of China (referred to as the Foundation) is a national public fund raising foundation dedicated to overseas Chinese education. The Foundation aims at promoting Chinese culture, developing Chinese education and advancing cultural exchanges. It plays a vital role in fund raising and promoting Chinese culture and language through multiple channels (China Education Foundation, 2018). It is pointed out in the 2018 Work Highlights of the Secretariat of the Chinese Language and Culture Education Foundation of China that in 2018, the focus of the Foundation is to raise funds, serve the overall situation of the overseas Chinese affairs work and the B\&R Initiative, train talents for the $B \& R$ construction, strengthen cooperation with relevant units, make good use of the $B \& R$ special funding, set up scholarships and support Chinese students studying in the B\&R countries to return to China for further studies (CLEF, 2018).

The Chinese Cultural Center established by the Ministry of Culture aims at strengthening exchange and cooperation with overseas cultures and enhancing mutual understanding with foreign people. Currently, China has established 35 cultural centers overseas, which are responsible for continuously organizing various Chinese language teaching activities, Sinologist exchanges, art exhibitions, cultural performances and sports competitions etc. so as to introduce Chinese history, culture, development and contemporary social life to other countries (Ministry of Culture, 2018). In 2017, the Ministry of Culture announced the $13^{\text {th }}$ Five-Year Plan on Cultural Development and Reform of the Ministry of Culture (referred to as the Plan). It proposed that by the end of the $13^{\text {th }}$ Five-Year period, the total number of overseas Chinese cultural centers will reach 50. The Plan also pointed out that it is necessary to vigorously promote the development of international Chinese and Chinese studies, strengthen cultural exchange and cooperation with countries along the B\&R (Ministry of Culture and Tourism, 2018).

\subsection{Development Policies of IECL Issued by Universities at Provincial and Municipal levels}

In addition to the government-based IECL and IECL promotion system, various provinces, cities and universities have also introduced special policies to promote the development of IECL. For example, relying on the Ministry of Education, Yunnan Province took full use of its geographical advantages of bordering the ASEAN countries by setting up the "China-ASEAN Education and Training Center" at Yunnan University, Yunnan University for Nationalities and Yunnan Agricultural University. The institution aims at providing Chinese teachers for Southeast Asian countries and emphasizing on helping Southeast Asian students to enhance their understandings of Chinese culture and Chinese language through the overseas Confucius Institutes. In 2016, Yunnan and Thailand co-established the institutionalized Yunnan-Thailand Cooperation Working Group and jointly organized the "Yutai Education Cooperation and Exchange Activity" to support each other in implementing language teaching activities and deepening educational cooperation and exchange between the two parties (Xinhua net, 2018).

By the time the "Maritime Silk Road" proposal was initiated, Fujian Province issued the $13^{\text {th }}$ Five-Year Development Plan on the Opening of Education in Fujian Province (referred to as the Plan), and established the "New Maritime Silk Road University Alliance" based on universities in Fujian Province. The universities have worked together with Southeast Asia, South Asia and other countries on building a platform for international cooperation and exchange of higher education, including 10 new Sino-foreign cooperative universities and 100 Sino-foreign cooperative education projects (Fujian. gov., 2018). The Plan clearly implemented the IECL Promotion Program, 2 newly established Confucius Institutes and 6 Confucius classrooms overseas to expand the teacher and volunteer talent pool throughout the development of IECL promotion as well as to formulate 
various international Chinese textbooks for more target-oriented IECL.

The Xinjiang Uygur Autonomous Region fully played its role as the window opened to Central Asia and the Middle East. Some famous universities, such as Xinjiang University and Shihezi University, in the autonomous region became the core region of education in the Central Asia along B\&R. In 2016, the Xinjiang Uygur Autonomous Region and 51 universities in Russia, Kazakhstan and other seven countries jointly established the "China-Central Asian National University Alliance". Until now, Xinjiang Uygur Autonomous Region has cooperated with multiple Central Asian universities and has established 7 Confucius Institutes and more than 70 Confucius classrooms, teaching places and Chinese Language Centers. The autonomous region has gradually become an important base for the cultivation of international cooperative talents in collaboration with neighboring countries (Ning, 2016).

\section{The Status Quo of IECL Development in Countries along the B\&R}

Since the proposal of the B\&R Initiative, Chinese universities at governmental, provincial and municipal levels have promoted a series of projects on the development of IECL and have achieved fruitful results. Under the new context of the B\&R Initiative, China's economic and cultural exchange with the rest of the world has become increasingly frequent. The number of students from B\&R countries who study in China and the number of overseas Confucius Institutes have been rising continuously, which therefore accelerated the internationalization of Chinese language.

\subsection{Countries along the B\&R Drives the Growth of International Students Studying in China}

The development of IECL in China is dominated by non-profit organizations and universities which took the responsibilities for IECL promotion. They mainly carry out Chinese teaching, Chinese testing and Chinese language teacher training. Under the initiative and influence of the B\&R Initiative, many foreign enterprises have flooded into China, which has created a surging demand for international talents who understand Chinese language, culture and social customs. Consequently, subjects with distinct cultural characteristics such as Chinese language, Chinese medicine, art and martial arts are highly popular among international students who are expected to be engaged in a wider cooperation between its own country and China after learning Chinese and Chinese culture.

The latest Report on a Study of China's Development released in 2017 showed that the total number of students studying in China in 2016 was 442,773, of which 207,746 were from countries along the B\&R. This number accounted for $46.9 \%$ of the total number of international students and witnessed an increase of $13.6 \%$ over the same period last year, which became a key point of growth in the number of students studying in China (Wang \& Miao, 2017). From the perspective of the country of origin, 10 countries with the largest number of students coming to China are from South Korea, the United States, Thailand, Pakistan, India, Russia, Indonesia, Kazakhstan, Japan and Vietnam. Apart from the United States, Japan and South Korea, the rest of countries are all B\&R countries. Among the B\&R countries, Thailand, Pakistan, India, Russia, Indonesia and Kazakhstan enjoyed a growth rate of more than $10 \%$ (Wang \& Miao, 2017). Such a rapid increase of international students coming to China from the $\mathrm{B} \& \mathrm{R}$ countries indicates that the demand of Chinese language learners worldwide was satisfied. On the other hand, more talents are cultivated for the B\&R construction, and the upsurge of Chinese learning around the world and the spread of Chinese culture are further promoted.

Currently, in addition to the Chinese language education undertaken by universities, international schools are also in a period of unprecedented development for overseas learners. Most students enrolled in international schools are non-international who came to China as children affiliated to ethic Chinese. Clearly, they can receive formal IECL education from international school. It is predicted that with the ever-rising number of foreigners settled and worked in China, Chinese education in international schools is undoubtedly a potential market in the future.

\subsection{The Scale of Confucius Institutes in Countries along the $B \& R$ Expands}

Compared with the domestic IECL market, the overseas IECL market, represented by the Confucius Institute as the main body for promoting Chinese language and culture, is much larger. Today, it has been an important platform to improve the soft power of Chinese culture and the internationalization of Chinese language teaching and cultural communication. Since the establishment of the first Confucius Institute in 2004, the Confucius Institute has been adhered to the "Going Out" strategy all along. So far, it has developed into a model of humanistic communication and international education cooperation in just a few decades, which has been accredited by many overseas media as "the best and most wonderful cultural products exported from China" (Newschina, 2018). 
The Confucius Institute is not originally designed for the B\&R Initiative, but since the B\&R covers more than 60 neighboring countries and a population of 4.4 billion, both from a conceptual perspective and a practical observation, the Confucius Institute could be regarded as the voice of Chinese education at home and abroad under the framework of "A Community with Shared Future", and an innovative practice for both Chinese language and Chinese culture to participate in the global governance. In February 2013, the Ministry of Education formulated the Confucius Institute Development Plan (2012-2020), which required that by 2015, the number of Confucius Institutes all over the world shall reach 500, accommodating 1.5 million students. By 2020, the global communication system of Chinese language shall be targeted to cover a wider range of industries, enabling Chinese language to be one of the most widely used language by foreigners (Ministry of Education, 2018). By 31 December of 2017, 525 Confucius Institutes and 1,113 Confucius Classrooms were established in 146 countries and regions around the world, with a total of 1.9 million students. Among them, 134 Confucius Institutes were along the B\&R regions, 127 Confucius Classrooms were settled in primary and secondary schools with 460,000 registered students and nearly 8,000 cultural events were held (Hanban, 2018). Among the countries along the B\&R, the construction of Confucius Institutes and classrooms are more prominent. For instance, 17 Confucius Institutes and 5 Confucius classrooms were set up in Russia; 15 Confucius Institutes and 20 Confucius classrooms in Thailand; 6 Confucius Institutes and 2 Confucius classrooms in Indonesia; 5 Confucius Institutes in Kazakhstan; 4 Confucius Institutes plus 21 Confucius classrooms in Kyrgyzstan (see Figure 1).

The status quo of the development of IECL shows that Southeast Asia is still the largest market for overseas IECL education. Due to historical reasons, in terms of cultural identity and demographic composition, there are still many similarities between China and Southeast Asia in culture, religion and social customs. In addition, Southeast Asia is the region with the largest number of ethnic Chinese. In Southeast Asia, Chinese language education exerts the most prominent influence because a certain number of Chinese schools are set up in all regions.

\section{Problems in the Development of IECL}

The above analysis shows that under the new background, the IECL has developed vigorously at both home and abroad and has achieved preliminary results. However, the analysis also reveals the short supply in the layout of IECL institutions in countries along the B\&R, three teaching problems including problems in teachers, teaching materials and teaching methods, as well as issues in resource allocation methods and IECL laws and regulations.

\subsection{The IECL Institutions are in Short Supply in Countries along the $B \& R$}

The number of Confucius Institutes and Confucius classrooms opened in the B\&R countries has been growing steadily each year. Nevertheless, with the internationalization of Chinese language, the demand for learning Chinese language has witnessed rapid increase. As a result, the existing Chinese language teaching and Chinese cultural communication institutions such as the Confucius Institutes, overseas Chinese Language Schools and overseas Chinese Cultural Centers are still in short supply in the countries along the B\&R. In other words, the current supply cannot fully satisfy the needs of Chinese learners from a global perspective. Taking the number of Confucius Institutes as an example, it can be observed from Figure 1 that by the end of 2017, the top numbers of overseas Confucius Institutes were mostly founded in economic advanced countries or developed countries. Among the top 20 countries, only 7 countries are B\&R countries, the disparity is still large comparing to the number in developed countries such as the US and the UK. Among the top 20 non-B\&R countries, the number of Confucius Institutes is 278 , accounting for $53 \%$ of the total number 525 . While the number of Confucius Institutes along the B\&R is 57 , accounting for only $10.9 \%$ among the total number of Confucius Institutes.

The above analysis shows that the layout of IECL institutions abroad is extremely unbalanced. Moreover, the distribution cannot adapt to the industrial cooperation and development pattern of the countries along the B\&R. Besides, the gap still looms large comparing to the potential needs for IECL promotion. 


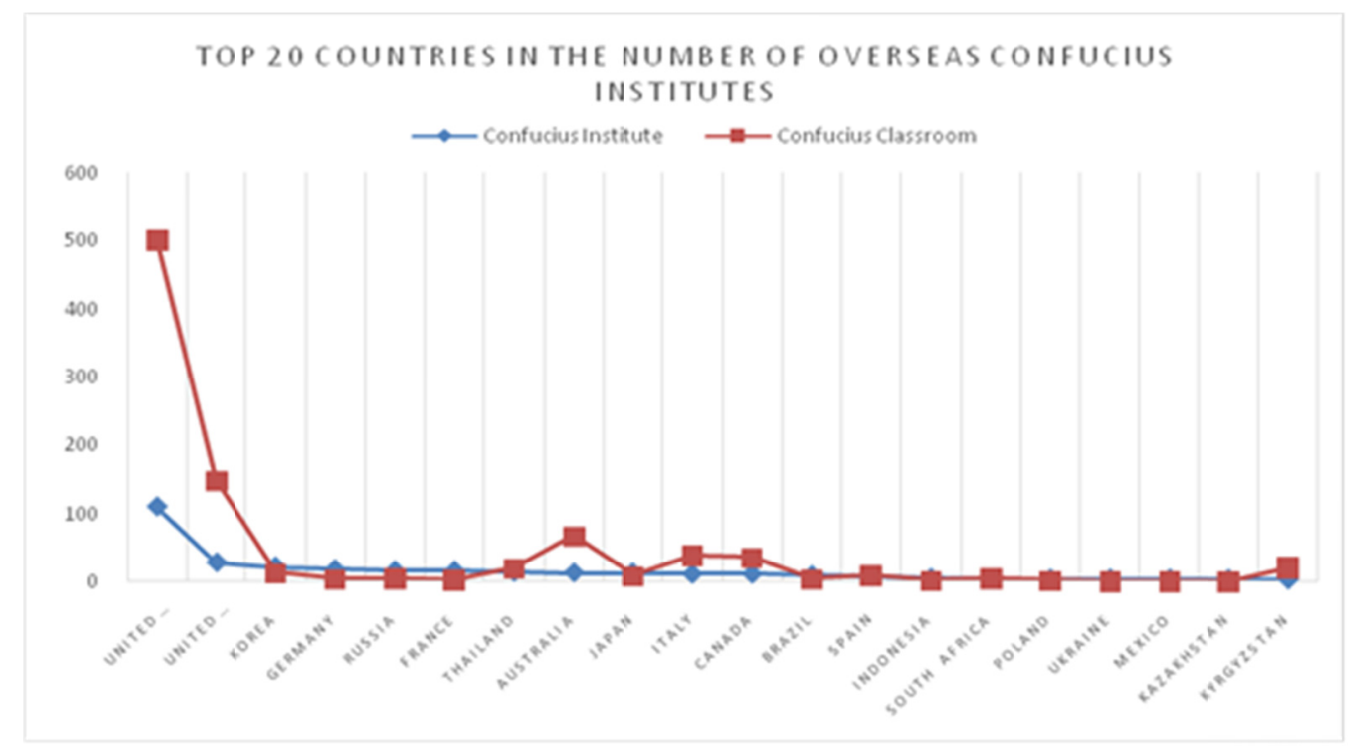

Figure 1. Top 20 countries in the number of overseas Confucius Institutes

Data Source: Confucius Institute Headquarters. (2018). About Confucius Institutes. Retrieved July 3rd, 2018, from http://www.hanban.edu.cn/confuciousinstitutes/node_10961.htm

\subsection{Large Gaps Exist in Chinese Teachers and Teaching Materials}

Among the three issues in teaching, the problem regarding to teachers is the core that should be dealt with in top priority. As for the shortage in Chinese teachers, data from various sources shows that there is a big disparity in the supply of IECL education talents, and such a gap is difficult to be filled in a short period of time. According to the International Association of Chinese Teachers, by 2016, the number of Chinese learners from foreign countries exceeded 150 million while the number of Chinese language teachers in the world exceeded 5 million (ITSCT, 2018). However, what is the number of Chinese teachers? In 2015, the Confucius Institute organized and trained 40,000 local teachers and sent 16,100 Chinese deans, teachers and volunteers abroad (Xu, 2016). So far, in China, there are more than 300 colleges and universities offering undergraduate and master's degree programs in IECL with an annual enrollment of around 15,000 students. It can be estimated that China will take at least 70 years to make up for the gap of 5 million Chinese teachers. Many international Chinese language schools and Confucius Institutes around the world will still face the shortage in professional Chinese teachers.

The main problem in Chinese textbooks is that they cannot be qualified the localization for Chinese learners. In recent years, the types and scales of Chinese textbooks have increased by a large margin. At present, there are more than 3,000 kinds of IECL textbooks published in China. However, facing a vast variety of Chinese textbooks, many Chinese teachers do not know exactly which to choose. A survey indicates that there is no shortage in the number of Chinese textbooks, instead, the main issue that hinders the textbooks from "going abroad" is the one so-called "de-localization" (Li \& Gong, 2015). The general Chinese textbooks published in China contain rich and difficult contents, but overlook the social environment and cultural customs of overseas learners who usually take fewer classes than those studies in China. Since the general textbooks are not necessarily suitable for practical teaching of Chinese overseas, many large and medium-sized foreign schools organize teachers to write local Chinese textbooks. In addition, since the proportion of Chinese teachers and textbook editors in Chinese colleges and universities is very limited, the funding and management system for expatriate teachers and researchers is still not sound. Many Chinese teachers and Chinese textbook writers are still lack of international visions. Due to their absent knowledge in the awareness of diverse environments, cultural backgrounds and learners' situation, they cannot design individualized learning materials for Chinese learners.

\subsection{The Distribution Method of IECL Service Product Is Single}

In most cases, IECL services receive resource allocation from three channels: the government, non-profit organizations and enterprises. However, judging from the current resource allocation of IECL service products, the three configuration methods have become unified as one method. The related IECL products and services is 
mainly provided by non-profit organizations and universities, which is a simplex resource allocation method. Meanwhile, private education institutions and enterprises can hardly survive in the market. As a government-led non-profit organization, the Confucius Institute has dominated the government's function of providing equal public products, so that the enterprises and social resources cannot be effectively utilized. Therefore, the monopoly scenario of the industry is inevitable (Wang, 2015). For example, one of the problems in Chinese textbooks among the three problems of teaching can accurately reflect the consumption preference in the market of Chinese language teaching. The textbooks could have been completely provided by some other publishing companies, in a way to improve the scale of Chinese textbook production and effectively improve the localization of Chinese textbooks. However, these products are only available from non-profit organizations such as the Confucius Institute, which consequently leads to the so-called industrial monopoly. This is contrary to the market law of IECL promotion and is not conducive to the sustainable development of IECL neither.

In addition, since enterprises cannot effectively enter the field of IECL service, they cannot play the role of market regulation in resource allocation, thus resulting in the lack of competition among non-profit organizations. The government and non-profit organizations are quite contradictory to civil businesses and enterprises; such phenomenon inevitably leads to an inefficient resource allocation and supply method. The three problems in Chinese language teaching show that merely relying on the government and non-profit organizations to provide IECL promotion model is not enough for meeting the needs of individualized and diversified market demand of IECL. Taking Chinese teacher training and dispatch as an example, because private educational institutions are not allowed to get involved in such a cause, the Confucius Institutes can only count on some universities to train Chinese teachers. Thus, teacher training and assignments become a monopoly under the government's control. Facts have proved that relying solely on the Confucius Institutes to train teachers cannot solve the problems of teachers' shortage; on the contrary, it will even widen the gap, which will have a negative impact on IECL and IECL promotion.

\subsection{Relevant Laws and Regulations of IECL and IECL Promotion Need to Be Improved}

As an important language resource communication institution in China, the Confucius Institute is inseparable from the system construction. Over the past two decades, as a new model for overseas cooperation in school running of China, the Confucius Institute has successfully communicated with abroad, spreading Chinese language and culture. It has continued to move forward through adjustments, thanks to a relatively mature set of regulations, such as the Charter of the Confucius Institute, Agreement between the Confucius Institute Headquarters and the Foreign Institutions on Cooperative Construction of Confucius Institutes, Teachers' Qualifications of the Confucius Institute and Chinese Funding Management Measures of the Confucius Institute to ensure the normal operation of the college. With the vigorous development of Sino-foreign cooperative education, more IECL institutions need to go abroad. However, in the face of new demands and development needs, other Sino-foreign cooperative education activities are only conducted based on the Regulations of School Running on Chinese-Foreign Cooperation of PRC issued by the State Council in 2003 and the Measures for the Implementationof School Running on Chinese-Foreign Cooperation of PRC issued by the Ministry of Education. Apparently, the existing Sino-foreign cooperative education system is inconsistent with the current development situation and is imperfect in terms of laws and regulations. Therefore, new overseas cooperative educational institutions are in a difficult situation to survive.

In addition, today's IECL services are facing a general environment with trade barriers, because many countries have set obstacles to the import of educational services. Due to the flaws in China's international and domestic legislation on education service trade, the Confucius Institute often encounters various disputes and conflicts in the process of going out and school running. Another major cause of disputes over overseas schooling is that, as a government-led language promotion agency, the Confucius Institute is always considered to be politically motivated by the government's excessive intervention in the process of overseas communication. Political prejudice and even problems such as exclusion and boycott often occur (Wang \& Ning, 2016).

\section{The IECL Development and Strategy under the B\&R Initiative}

Regarding to the above problems, it is crucial to study how to establish countermeasure policies for the development of IECL to serve the B\&R construction. We believe that IECL and IECL promotion must follow the countermeasures of "bringing in" and "going out", improve the legislation and system construction of the Confucius Institute, actively promote the innovation of IECL methods, support private educational institutions under the government's leadership, and the role of enterprises in IECL and IECL promotion.

\subsection{The IECL Development Strategy of "Bringing in"}

To better promote the development of IECL in the countries along the B\&R, we must adhere to the policy of 
"bringing in", speed up the policy of encouraging Chinese language teachers and Chinese learners from B\&R countries to study in China and promote international students to understand Chinese language and Chinese culture.

Firstly, the government should continue to increase the amount of grants for international students from B\&R countries, and provide more favorable policies support B\&R countries and encourage more international students in Chinese major and local Chinese teachers to pursue further studies abroad, enhance language skills and return to homeland after the completion of studies to conduct Chinese language training for local students. At present, the "Silk Road" scholarship established by the Chinese government has the widest coverage and the largest amount. According to the statistics of the Ministry of Education, in 2016, a total of 49,022 international students from 183 countries received Chinese government scholarships, of which 61\% students came from B\&R countries (MOE, 2018). Among students from B\&R countries, about 38\% majored in Chinese, and 366 graduates of IECL from 43 countries have returned to their home countries to conduct Chinese language training. They have helped expanding the platform and development space for the internationalization of Chinese education $(\mathrm{Xu}, 2016)$. However, in $\mathrm{B} \& \mathrm{R}$ countries which prevail differences in cultural background and Chinese proficiency, the number of overseas Chinese teachers is far from enough. In this case, China needs to improve the discipline construction of IECL in colleges and universities and improve the professional level of Chinese teachers. At the same time, China should further expand the government scholarship program, increase financial support for international students from B\&R countries, and gradually provide schools with free rights to set tuition fees and change the way of financial support for international students from hidden subsidies to specific funds, thus attracting more outstanding overseas talents.

Secondly, all universities at provincial and municipal levels should give full play to their regional and own advantages, carry out targeted overseas cooperation and education with the countries along the $B \& R$, and strengthen academic activities and cultural exchanges with overseas institutions. For example, Yunnan and Guangxi are in collaboration with the ASEAN; Xinjiang is in collaboration with Central Asia. Such models can also be applied to other regions, for instance, the northeast China can conduct educational cooperation with Northeast Asian countries, and the Inner Mongolia Autonomous Region can exchange and cooperate with Mongolia. The eastern China can take advantage of its developed economy and rich educational resources to attract more Chinese language talents by setting up the B\&R Exclusive Scholarship and conducting overseas enrollment promotion. For example, Beijing has taken the lead in setting up the B\&R Exclusive Scholarship to attract full-time academic students and Chinese language talents from B\&R countries. South China University of Technology in Guangdong Province held academic exchanges with international students from Thailand, Vietnam, Russia and other countries through the establishment of short-term Chinese training courses, holding Chinese enrollment publicity activities and more events.

Lastly, all colleges and universities should be well prepared in the service provision to international students in China, strengthen the construction of official websites of the colleges and universities, provide explicit and rich information access channels for international students and promote the integration of international students into Chinese culture. Compared with English-speaking countries such as Britain, the United States and Australia, China has inherent disadvantages in attracting international students. Although in recent years, a variety of exchange activities were held in the B\&R regions, yet for many international students, the way to know Chinese universities is still limited, being resisted to solely relying on the official website of the universities. At present, some English websites belonging to a few colleges and universities are still not comprehensive. A common scenario is the lack of essential information for international students to apply for their overseas university, such as school profiles, departmental settings, admissions brochures and cooperation exchanges. Therefore, universities should strengthen the construction of Chinese and English websites and enhance the management of normalized information so that overseas applicants can better understand Chinese universities. In addition, in terms of accommodation, for most of the universities, international students are arranged in international student apartments with few opportunities to contact with Chinese students, which is not beneficial for them to practice Chinese and integrate into Chinese culture. Consequently, colleges and universities should try to change the accommodation arrangement for international students, encourage them to participate in the Chinese Student Associations, interact with Chinese students and promote cross-cultural communication.

\subsection{The IECL Development Guidance of "Going Out"}

As an important base for IECL, the Confucius Institute bridges the communication among countries along the $\mathrm{B} \& \mathrm{R}$. In a sense, the contribution of Confucius Institutes manifested in the construction of the B\&R will become ever more prominent as time goes by. Therefore, we must adhere to the principle of "going out" for better promoting Chinese language and culture. 
First, we must optimize the layout of language and cultural communication institutions such as the Confucius Institutes along the B\&R from the national level. In July 2016, the Ministry of Education issued a notice known as the Education Action in Promoting the Belt and Road Initiative. The Action proposed that governments at all levels should promote language intercommunication along the route, jointly train and cultivate high-level language talents, galvanize more social strength to support Confucius Institute and Confucius classroom construction, strengthen the cultivation of Chinese teachers and Chinese teaching volunteers, and fully satisfy the needs of Chinese learning in the countries along the route (MOE, 2018). As for the overall layout of the Confucius Institute, we can learn some experience and achievements from the overseas language and culture communication institutions in developed countries, such as the British Council, the Court Union, the Cervantes Institute, and the Goethe Institute. By following the laws of language and cultural communication, we will focus on the development of language and cultural communication institutions along the B\&R countries and form a distribution pattern centered on the $\mathrm{B} \& \mathrm{R}$ economic and trade cooperation. By doing so, we will not only meet the needs of people from various regions to learn Chinese, but also promote the strategy of "going out" for Chinese language and culture, so as to facilitate the construction of the B\&R.

Second, we need to enable more Chinese teachers and volunteers to go overseas to learn foreign language and culture, provide trainings to foreign language teaching professionals, and fill the huge job vacancies. It is suggested that China should strengthen the competitiveness of IECL professionals, increase the funding for IECL teachers and students to go abroad for further study, so that more Chinese professionals can go abroad to understand the customs of foreign countries on a basis of educational theory. In addition, to meet with the opportunities of the B\&R, the training of IECL teachers should be combined with the industrial cooperation and development along the B\&R countries, focusing on the cultivation of top talents who understand both language and professional knowledge. Besides, in terms of the edition of Chinese textbooks, we should follow the principle of diversification and give full play to the advantages of general textbooks. At the same time, we should fully consider the culture, religion and life of the countries along the B\&R, as well as the differences in habits, prepare Chinese textbooks with distinct features of each nation, establish various language and culture minor courses and construct a Chinese language teaching system according to local conditions.

Third, we shall offer more chances for enterprises to go overseas while taking the IECL promotion as the core productivity and major push for enterprise development. Enterprises which involved in the B\&R economic and trade cooperation should utilize and integrate language resources while pursuing economic benefits. Such practices include offering Chinese language training classes for local employees and promote Chinese culture in the host country. Meanwhile, enterprises should also offer foreign language training courses for Chinese employees. By strengthening the construction of language skills, employees are expected to communicate in two or more languages. The construction of language capability in enterprises may not only help Chinese and foreign employees to get familiarize with each other's culture and language, eliminate psychological barriers, truly realize the people-to-people bond, improve the working efficiency of enterprise, accelerate the construction of the B\&R, obtain long-term local economic revenues and achieve sustainable development.

\subsection{Improvements on the Legislative and Institutional Construction of the Confucius Institute}

It is necessary to improve the legislation and system construction of the Confucius Institute as soon as possible to ensure the sustainable development of overseas Confucius Institutes. First of all, the legislation regarding to the Confucius Institute should be visionary. Under the general trend of internationalization of higher education, as part of the international trade, education service trade is increasingly active. It is time for China to formulate a unified Trade Law on Education Service as soon as possible to guide and standardize affairs of education service trade, accelerate the establishment of a sound legal system for education internationalization and provide the legislative basis for the overseas Confucius Institute. In such a fundamental way, we need to aim at resolving the disputes relating to Confucius Institutes overseas. Secondly, it is necessary to consider the fact that the Confucius Institute has a relatively short history and insufficient experience in terms of school running, so it is imperative to improve the school-running system, and strive to explore and discover a more complete evaluation and elimination mechanism for Confucius Institutes. Actions should be taken to suspend, rectify or replace overseas Confucius Institutes with unsatisfactory quality in schools running. If there is still insignificant improvement, the Confucius Institute Headquarters should consider to close related schools to avoid taking up too much funding and resources by the unqualified Confucius Institutes. The goal is to effectively prevent and resolve various disputes and negative influences that occur during the school-running process, ensuring the sustainable development of overseas Confucius Institutes. Finally, it is necessary to learn from the successful experience of the Confucius Institute system construction and learn from the lessons exposed during the development. Related bodies should take the ever-improving legislation of the Confucius Institute as a preliminary work of the 
Sino-foreign cooperative education legislation, and constantly advance the laws and regulations to solve the inconsistent and contradictory issues between the existing of Sino-foreign laws and regulations on cooperative education and the actual development, so that the new Sino-foreign cooperative education activities will be law-based while going abroad.

\subsection{Active Innovations on the IECL}

In the new era of "Internet+", apart from the IECL strategies of "bringing in" and "going out", the new model is to take digital media as the core and conduct IECL and IECL promotion by using the Internet, cloud computing and Internet of Things (IoT). This model has become one of new emerging models of IECL and IECL promotion which enjoys an increasingly important role. In October 2017, General Secretary Xi Jinping pointed out in the report on the $19^{\text {th }}$ National Congress of the CPC that China should tightly coordinate with the B\&R construction and develop Chinese language and foreign humanities exchanges with prior orientations of countries along the route. We need to perform duties in overseas study, Chinese teaching, cultural communication, mutual degree recognition and other works. It is also imperative for universities, middle and primary schools to strengthen "Internet + language teaching+ humanities communication" and support the "going out" movement of representative projects such as Chinese language, Chinese medicine, folklore and martial arts (MOE, 2018).

In response to the uneven distribution of Chinese education resources in surrounding areas of the $\mathrm{B} \& \mathrm{R}$, different time zones of Chinese learners and various learning levels, the Online Confucius Institute adopted the "Internet +" teaching method to satisfy the needs of Chinese learners in different levels and regions. By using the all-media teaching facilities to balance Chinese teaching resources and to achieve personalized teaching, the Online Confucius Institute has become one of the most excellent comprehensive Chinese language teaching websites. By 2015, the Online Confucius Institute users reached 8 million from more than 200 countries, including 500,000 registered students (Zheng, 2015). With the ever-increasing enrichment of online education resources, MOOC (a teaching model with the development and utilization of micro-video teaching resources as the core technology) has also been widely used in Confucius Institutes. MOOC teaches based on learner's current Chinese level, provides personalized education according to their learning habits and cultural differences and creates a realistic language environment to improve Chinese learning proficiency (Lei, 2015). With the further development of online education resources and technology, a large number of overseas Chinese learners will have opportunities to learn Chinese via the Internet.

Compared with the traditional teaching model, the Chinese teaching model based on the Internet reflects the diversification feature of Chinese learning. Through the online platform, students can adjust their learning time and learning content at will. Meanwhile, the way of imparting knowledge has also been changed, making it easier to be mobilized with students' self-learning ability. Therefore, language and culture communication agencies should be aware of the value-added effects of the combination of IT development and Chinese education. Universities, middle and primary schools in each province and city should actively promote the "Internet +" teaching model for Teaching Chinese to Speakers of Other Languages (TCSOL), use Chinese mobile terminals and mobile networks to conduct Chinese language teaching, make use of the cloud platform to share and manage teaching resources and highlight the effectiveness of new educational tools in Chinese language and culture promotion. At the same time, standards of online Chinese teachers and teaching evaluations should be established to expand studies on Chinese teaching applications, including research on online Chinese learners and learning behavior, data mining technology and micro-skills for fragmented learning, thereby improving the efficiency of Chinese teaching, Chinese cultural communication and expanding the international popularity of Chinese.

\subsection{Attentions to Private Educational Institutions and Enterprises}

The development and promotion of IECL is inseparable from the promotion and support of the government. In other words, if a country wants to effectively develop and strengthen language and cultural communication institutions, one must rely on the leading role of the government. The promotion of Chinese culture and the construction of Confucius Institutes have achieved world-renowned achievements in just a few decades. Thanks to the unified leadership of the government, all departments have worked jointly. For the development of transnational educational institutions with main contents of language and cultural communication, the government, non-profit organizations and enterprises should participate in the operation process to create a win-win result. However, the question of how to balance the "governmental driving force" and the "market operation" is still an urgent issue that Chinese language and cultural education institutions need to cope with. Therefore, while recognizing the leading role of the government in IECL and IECL promotion, we should also alter resource allocation of IECL as soon as possible, encourage state-owned and private enterprises to 
participate in IECL and IECL promotion to eliminate cultural protectionism from official institutions encountered by cultural communication agencies overseas.

Firstly, the government needs to improve the institutional construction and clarifies the functions of government, non-profit organizations and enterprises in the IECL and IECL promotion. In 2016, the General Office of the Central Committee of the Communist Party of China and the General Office of the State Council issued the Opinions on Reforming the Management System of Social Organizations to Promote the Healthy and Orderly Development of Social Organizations (referred to as the Opinions). It proposed to exhibit the complimentary cooperative roles of social organizations in foreign economy and culture, as well as in the exchanges of science and technology, sports, environmental protection and more, strengthen its important platform functions foreign exchange at civil levels (Ministry of Civil Affairs, 2018). According to the Opinions, the government should also pay attention to market rules while establishing scientific management mechanisms of cultural communication institutions and provide diplomatic support and publicity for private educational institutions to set up Chinese language teaching bases overseas. The government is suggested to allow private educational institutions and enterprises to enter the market and provide IECL products and service, integrate these civil institutions into the IECL promotion system, and receive unified supervision and management by the government.

Secondly, on the one hand, it is necessary for the government to set up a special funding to support private educational institutions which can meet the requirements to conduct foreign language teacher training and foreign language online teaching construction, to reduce overseas cultural resistance or protectionism to our cultural output and ensure the comprehensive development of IECL. On the other hand, companies which conduct the IECL should seize the huge business opportunities in the core industries of TCSOL, Chinese language training exams and teacher training.

\section{Conclusion}

Under the new situation, IECL and IECL promotion are undergoing unprecedented opportunities and challenges. The increasing number of international Chinese learners in China and the continuous expansion of overseas Confucius Institutes have opened the door of IECL. However, while the IECL is enjoying increasing popularity, it has also encountered a series of problems. Based on the current IECL system, plus the development status and features of IECL, we now have put forward some constructive opinions on the development of IECL. In terms of the IECL development, we must adhere to the countermeasures of "bringing in" and "going out". Also, the government needs to pay more attention to countries along the $B \& R$ and cultivate more outstanding local Chinese teachers. In terms of the construction of Confucius Institutes, it is necessary to focus on optimizing the Confucius Institute or class design for countries along the B\&R to allow more Chinese teachers and volunteers to go overseas. It is also required to improve the legislation and institutional construction of overseas Confucius Institutes as soon as possible to maintain the sustainable development of Confucius Institutes overseas. As for teaching methods, teachers shall make full use of teaching models and teaching resources, such as using the Internet as a teaching medium. Finally, in terms of government responsibility and market operation, the IECL development shall be government-based. At the same time, it should pay attention to market rules and enhance the responsibility of private educational institutions and enterprises in the IECL and IECL promotion, so as to meet the needs of Chinese language learners in the growing market through resource allocation.

\section{References}

Chen, T. (2017). The Opportunity and Challenge of Chinese International Communication under 'One Belt and One Road' Initiative Strategy. Journal of Qinghai Normal University, 39(2), 6-10.

China Chinese Education Foundation. (2018). Foundation Introduction. Retrieved from http://www.clef.org.cn/jjhjs/index 1. shtml

China Chinese Education Foundation. (2018). The 9th meeting of the 3rd Council of China Education Foundation was held in Beijing. Retrieved from http://www.clef.org.cn /news/2018/0207/5/2059.shtml

Confucius Institute Headquarters. (2014). Confucius Institute's 10-year development review. Retrieved from http://news.china.com.cn/world/2014-09/15/content_33514532.htm

Confucius Institute Headquarters. (2017). The 12th Confucius Institute Conference ended successfully. Retrieved from http://www.hanban.edu.cn/article/2017-12/13/content_711520.htm

Confucius Institute Headquarters. (2018). About Confucius Institute. Retrieved from http://www.hanban.edu.cn/confuciousinstitutes/node_10961.htm

Du, M. (2016). The International Communication of Chinese Language and Its Characteristics on the 
Background of One Belt and One Road. Journal of Qinghai Normal University, 5, 134-140.

International Chinese Teachers Association. (2016). The gap between Chinese and foreign teachers is large, and the status quo of teachers is two days. Retrieved from http://www.itact.com.cn/hyzx/2016 /0117/5843.html

Ke W. J. (2017). Research on the Sino-foreign Cooperative Education in the Environment of 'One Belt One Road'. Paris: Atlantis Press.

Lei, L. (2015). Application and Significance of Data Mining Technology in Micro Video Teaching of Confucius Institutes. Journal of Yibin University, 3, 106-112.

Li, Q., \& Gong, X. (2015). General, Regional, Contextual, and Country-On the Diversification of International Chinese Textbooks. Chinese Language Learning, 1, 76-84.

Li, S. B., \& Wu, J. (2013). Research on Chinese High Efficiency International Promotion. Beijing: Science Press.

Ministry of Civil Affairs of the People's Republic of China. (2016). The State Council Office issued the "Opinions on Reforming the Management System of Social Organizations to Promote the Healthy and Orderly Development of Social Organizations". Retrieved from http://www .mca.gov.cn/article/zwgk/mzyw /201608/20160800001526.shtml

Ministry of Culture and Tourism of the People's Republic of China. (2017). Ministry of Culture on the "Thirteenth Five-Year Plan" Cultural Development Reform Plan. Retrieved from http://zwgk.mcprc.gov. Cn/auto255/201702/t20170223_491392.html

Ministry of Culture of the People's Republic of China. (2017). Main duties of the Ministry of Culture. Retrieved from http://www.mcprc.gov.cn/gywhb/zyzz/201705/t20170502_493564.htm

Ministry of Education of the People's Republic of China. (2013). Confucius Institute Development Plan (2012-2020). Retrieved from http://www.moe.gov.cn/jyb_xwfb/gzdt_gzdt/s5987/201302/t20130228_ 148061.html

Ministry of Education of the People's Republic of China. (2016). Notice of the Ministry of Education on Printing and Distributing the Educational Action on Promoting the Construction of the Belt and Road Initiative. Retrieved from http://www.moe.edu.Cn/srcsite/A20/s7068/201608/t20160811_274679.html

Ministry of Education of the People's Republic of China. (2017). A powerful force to promote the progress of human society to maintain a strong bond of world peace. Retrieved from http://www.moe.gov.cn/jyb_xwfb/ moe_176/201712/t20171222_322185.html

Ministry of Education of the People's Republic of China. (2017). The data of international students coming to China along the "Belt and Road" countries has increased significantly. Retrieved from http://www.moe.edu.cn/jyb_xwfb/xw_fbh/moe_2069/xwfbh_2017n/xwfb_170301/170301_mtbd/201703/t2 0170302_297943.html

Ning, J. M. (2016). Confucius Institute Research and Development Report. Beijing: The Commercial Press.

Notice of the People's Government of Fujian Province. (2016). The General Office of the People's Government of Fujian Province on Printing and Distributing the Special Plan for the Development of the 13th Five-Year Plan for Education in Fujian Province. Retrieved from http://www.fujian .gov.cn/zc/zxwj/szfbgtwj/201605/ t20160513_1169485.htm

Overseas Chinese Affairs Office of the State Council. (2017). Reply of the Overseas Chinese Affairs Office of the State Council to Proposal No. 0346 of the Fifth Session of the 12th National Committee of the Chinese People's Political Consultative Conference. Retrieved from http://www.gqb.gov.cn/news/2017/0725/43069. shtml

Propaganda Department of the Central Committee of the Communist Party of China. (2016). General Secretary Xi Jinping's series of important speeches. Beijing: Learning Press.

Wan, X. M. (2017). Research on the international promotion of Chinese in the process of 'One Belt And One Road'. Jiangxi Social Sciences, 37(4), 236-241.

Wang, H. L., \& Ning, J. M. (2016). Moderate Intervention: Government Behavior Choice in the Development of Confucius Institutes. Journal of Yunnan Normal University (Philosophy and Social Sciences Edition), 48(1), 54-61.

Wang, J. Q. (2015). Research on Chinese International Communication under the Background of Global 
Cultural Competition. Beijing: The Commercial Press.

Wang, T. W. (2015). The Status Quo and Countermeasures of International Chinese Teacher Professional Development. Journal of Northeast Normal University (Philosophy and Social Sciences Edition), 2, 229-231.

Wang, Y. H., \& Miao, L. (2017). China's study abroad development report. Beijing: Social Sciences Academic Press.

Xinhuanet. (2016). 2016 Yutai Education Cooperation and Exchange Event was held in Kunming. Retrieved from http://www.yn.xinhuanet.com/2016ynnews/20160711/3269553_c.html

$\mathrm{Xu}, \mathrm{L}$. (2016). Report on the work of the Confucius Institute Headquarters in 2015. Confucius Institute, 1, 10-17.

Zheng, Y. Q. (2015). New Ideas of Chinese International Education in the Background of Information Technology in the New Era. International Chinese Teaching Research, 2, 26-33.

\section{Copyrights}

Copyright for this article is retained by the author(s), with first publication rights granted to the journal.

This is an open-access article distributed under the terms and conditions of the Creative Commons Attribution license (http://creativecommons.org/licenses/by/4.0/). 